\title{
Functionalized polymer networks: synthesis of microporous polymers by frontal polymerization
}

\author{
N S PUJARI, A R VISHWAKARMA, T S PATHAK, A M KOTHA and \\ S PONRATHNAM* \\ Chemical Engineering and Process Development Division, National Chemical Laboratory, Pune 411 008, India
}

MS received 7 August 2004; revised 28 September 2004

\begin{abstract}
A series of glycidyl methacrylate (GMA)-ethylene dimethacrylate (EGDM) copolymers of varying compositions were synthesized by free-radically triggered thermal frontal polymerization (FP) as well as by suspension polymerization (SP) using azobisisobutyronitrile [AIBN] as initiator. The two sets of copolymers were characterized by IR spectroscopy and mercury intrusion porosimetry, for determination of epoxy number and specific surface area. Frontal polymerization was more efficient, yielding greater conversions at much shorter reaction times. The self-propagating frontal polymerization also generates microporous material with narrow pore size distribution. It yields higher internal pore volume and surface area than suspension polymerization, surface morphologies are, however, inferior.
\end{abstract}

Keywords. Poly[GMA-co-EGDM]; frontal polymerization; suspension polymerization; porosity; pore size; mercury intrusion porosimetry.

\section{Introduction}

Synthesis of porous poly(glycidyl methacrylate-co-ethyleneglycol dimethacrylate) [poly(GMA-EGDM)] by suspension polymerization was first reported in late 1970s. Macroporous beaded polymers (Wijnhoven and Vos 1998), with permanent porous structure, are formed by the presence of an inert porogen in the polymerization reaction and these find wide use. The porogen may either be an organic solvent which is miscible with the monomers (Horak et al 1981; Lewandowski et al 1998b; Hamid et al 1999) or a linear polymer which is soluble in the monomer phase (Liang et al 1997). The internal macroporous morphology is characterized by interconnected channels (pores), which permeate the rigid, extensively crosslinked polymer matrix.

Porous polymers prepared by suspension polymerization (SP) (Yuan et al 1991; Vivaldo-Lima et al 1997), have been used as chromatographic materials (Palm and Novotny 1997; Xie et al 1997; Tennikov et al 1998), in immobilization of enzymes (Maugh 1984; Fulton et al 1991), as catalytic surface and supports (Tanev et al 1994; Deleuze et al 1998), in separation and adsorbent media (Bhave 1991; Akolekar et al 1998; Lewandowski et al 1998a), as solid-supported reagent, and supports for combinatorial synthesis (Hodge and Sherrington 1980; Sherrington 1998) etc. Molecules diffuse freely through the pores, which form a maze of tortuous interconnected cavities of different sizes.

\footnotetext{
*Author for correspondence
}

Recent advances in polymer chemistry have led to the development of monomers and initiation agents providing propagating polymerization fronts (frontal polymerization, FP), driven by the exothermicity of the polymerization and the transport of heat from the polymerized product to the monomer. Russian workers studied the phenomenon extensively after the first observations were reported by Chechilo in 1972 (Chechilo et al 1972; Enikolopyan et al 1974; Khaunkaev et al 1974; Chechilo and Enikolopyan 1975; Davtyan et al 1975, 1976, 1977, 1984, 1985, 1986, 1989; White and Kim 1992, 1993). Pojman et al (Pojman 1991; Pojman et al 1992, 1993, 1995a,b, 1996a,b, 1997, 1998, 2000, 2003) triggered considerable excitement in both fundamental and applied aspects of frontal polymerization. The use of this mode of polymerization has many applications including rapid curing of polymers without external heating (White and Kim 1992, 1993), uniform curing of thick samples, solventless preparation of polymers such as thermochromic material (Pojman et al 1995a,b), hydrogels (Washington and Steinbock 2001), polyurethane (Fiori and Mariani 2003), functionalized crosslinked polymer networks (Pujari et al 2004), GRIN material (Koike et al 1988; Zhang et al 1997; Masere et al 2001) (by isothermal FP) and in synthesizing copolymers (Tredici et al 1998; Perry et al 2003). One important limitation of this process is that the fronts extinguish when they try to propagate through channels that are either too narrow due to conductive heat losses or too wide, due to convective heat losses driven by buoyancy-induced flow. Even when extinction does not occur, convective and buoyant instabilities can affect the struc- 
ture and properties of the resulting polymerized materials as well as the propagation rates of the fronts.

The synthesis of functional poly(GMA-EGDM) by frontal polymerization, in the absence of a porogen, is reported here. Infrared spectra, epoxy number, pore volume and surface area of these copolymers are compared with copolymers of similar composition synthesized by traditional suspension polymerization.

\section{Experimental}

\subsection{Materials and methods}

2.1a Material: Glycidyl methacrylate (GMA) and ethylene dimethacrylate (EGDM) obtained from Sartomer, USA, were used as received to prepare GMA-EGDM copolymers. Poly(vinyl pyrrolidone) [PVP] (Polysciences, USA) was used as protective colloid without further purification. Azobisisobutyronitrile [AIBN], (SISCO India) was recrystallized from methanol before use as initiator.

2.1b Methods: (i) Frontal polymerization: To synthesize $25 \%$ crosslinked density (CLD) copolymer, 5.9 mL GMA was mixed with $2.3 \mathrm{~mL}$ EGDM and $0.2 \mathrm{~g}$ AIBN in a 12 (i.d.) $\times 125 \mathrm{~mm}$ thick walled test tube marked in $1 \mathrm{~mm}$ units. Polymerization was initiated by means of solder gun $\left(>250^{\circ} \mathrm{C}\right)$, propagation of front was observed immediately and it went to completion with a velocity of $0.61 \mathrm{~cm} / \mathrm{min}$. Similarly, other copolymers were synthesized (table 1). Copolymers were ground using a blender, purified by washing several times with methanol, water and dried in vacuum oven at $50^{\circ} \mathrm{C}$ for $36 \mathrm{~h}$.

Stopwatch was used to time the front. Velocity, distance traveled by front per minute, was also effectively measured by coating the test tube with thermochromic material. Thick walled test tubes marked in $1 \mathrm{~mm}$ units were used for all experiments. A thermocouple of diameter $0.125 \mathrm{~mm}$ (Hi-Tech scientific, India) was inserted into

Table 1. Copolymerization of glycidyl methacrylate and ethylene dimethacrylate by frontal (FP) and suspension polymerization (SP).

\begin{tabular}{lccccrc}
\hline $\begin{array}{l}\text { Ex. No. } \\
\text { FP }\end{array}$ & $\begin{array}{c}\text { GMA } \\
(\mathrm{mL})\end{array}$ & $\begin{array}{c}\text { GMA } \\
(\mathrm{mol})\end{array}$ & $\begin{array}{c}\text { EGDM } \\
(\mathrm{mL})\end{array}$ & $\begin{array}{c}\text { EGDM } \\
(\mathrm{mol})\end{array}$ & $\begin{array}{r}\text { CLD } \\
(\%)\end{array}$ & $\begin{array}{l}\text { Ex. No. } \\
\text { SP }\end{array}$ \\
\hline G1111F & $5 \cdot 9$ & $0 \cdot 0486$ & $2 \cdot 3$ & $0 \cdot 0122$ & 25 & $\mathrm{G} 1111 \mathrm{~S}$ \\
$\mathrm{G} 2111 \mathrm{~F}$ & $4 \cdot 6$ & $0 \cdot 0379$ & $3 \cdot 6$ & $0 \cdot 0191$ & 50 & $\mathrm{G} 2111 \mathrm{~S}$ \\
$\mathrm{G} 2111 \mathrm{~F}$ & $3 \cdot 8$ & $0 \cdot 0313$ & $4 \cdot 4$ & $0 \cdot 0233$ & 75 & $\mathrm{G} 2111 \mathrm{~S}$ \\
$\mathrm{G} 4111 \mathrm{~F}$ & $3 \cdot 2$ & $0 \cdot 0264$ & $5 \cdot 0$ & $0 \cdot 0265$ & 100 & $\mathrm{G} 4111 \mathrm{~S}$ \\
$\mathrm{G} 5111 \mathrm{~F}$ & $2 \cdot 5$ & $0 \cdot 0206$ & $5 \cdot 7$ & $0 \cdot 0302$ & 150 & $\mathrm{G} 5111 \mathrm{~S}$ \\
G6111F & $2 \cdot 0$ & $0 \cdot 0165$ & $6 \cdot 2$ & $0 \cdot 0329$ & 200 & G6111S \\
\hline
\end{tabular}

Frontal polymerization: In all reactions $0.2 \mathrm{~g}$ of AIBN was used and copolymerization were initiated by means of solder gun; Suspension polymerization: $0 \cdot 2 \mathrm{~g}$ of AIBN was used, the reactions were continued for $3 \mathrm{~h}$ at $70^{\circ} \mathrm{C}$ at $300 \mathrm{RPM}$; CLD $=$ $\{[\mathrm{EGDM}] /[\mathrm{GMA}]\} \times 100$. the reaction mixture comprising monomers and initiator charged in the test tube. Temperature was measured as a function of time with programmable temperature controller (Hi-Tech scientific, India).

(ii) Suspension polymerization: The synthesis was conducted in double walled cylindrical reactor fitted with eight bladed Ruston turbine stirrer and nitrogen inlet. The continuous phase comprised of one weight percent aqueous solution of PVP. The discontinuous organic phase consisted of GMA, crosslinking divinyl monomer (EGDM) and polymerization initiator [AIBN]. The discontinuous organic phase was introduced into the aqueous phase, stirring was set at 300 rotations per min and the temperature was maintained at $70^{\circ} \mathrm{C}$ by circulating hot water. The reactant compositions were identical to those used in FP. The polymerization was continued for $3 \mathrm{~h}$. The copolymer obtained in beaded form was separated by decantation, washed with water, methanol and dried at room temperature under reduced pressure. The composition of synthesized GMA-EGDM copolymers are presented in table 1 .

Both sets of copolymers from frontal and suspension were sieved using Kumar test sieves (Mumbai, India), to obtain uniform particles of similar size range (80-100 mesh), used for characterization.

\section{Copolymer characterization}

\subsection{Epoxy number}

The surface epoxy functional groups of copolymers synthesized were estimated titrimetrically (Lee and Neville 1967). Millimole of epoxide per gram of polymer was estimated from addition of hydrogen halide to epoxy group (end group analysis).

\subsection{Infrared spectra}

A Shimadzu 8300-Fourier transform infrared spectrophotometer (FTIR) with a resolution of $1 \mathrm{~cm}^{-1}$ in the transmission mode was used. The copolymers were milled (2 $\mathrm{mg}$ each), mixed with potassium bromide $(100 \mathrm{mg})$, and pressed into a solid disk of $1.2 \mathrm{~cm}$ diameter prior to infrared measurement. Table 4 represents the characteristic peaks of the poly(glycidyl methacrylate-co-ethylene dimethacrylate) of similar copolymer composition $(100 \%$ CLD) obtained by the two methodologies.

\subsection{Mercury porosimetry}

The pore size distribution and pore volume of the copolymers were studied by mercury intrusion porosimetry in the pressure range $0-4000 \mathrm{~kg} / \mathrm{cm}^{2}$ with an Autoscan 60 mercury porosimeter from Quantachrome (USA). The mercury contact angle was $140^{\circ}$. 


\subsection{Specific surface area}

The specific surface area measurements, based on single point nitrogen adsorption method more popularly known as BET method, were conducted using Quantachrome Corp, USA.

\subsection{Surface morphology}

General morphological elucidation of poly(glycidyl methacrylate-co-ethylene dimethacrylate) [GMA-EGDM] beads was carried out by mounting dried poly[GMA-EGDM] beads on stubs and sputter-coating with gold to be able to visualize the beads. Micrographs were taken on a JEOL JSM-5200 SEM instrument.

\section{Results and discussion}

The general reaction scheme used for the synthesis of GMA-EGDM copolymers is presented in figure 1. Free radical FP is triggered by the complete decomposition of initiator followed by Arrhenius reaction kinetics (Pojman et al 1996b, 1998). Reaction continues in a localized re-
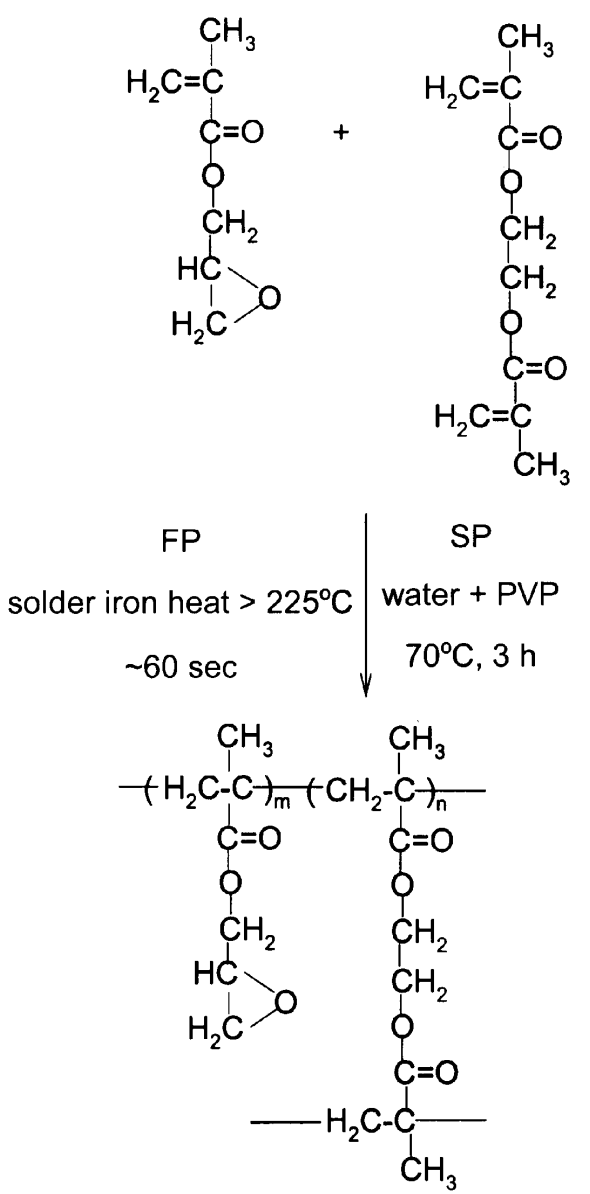

Figure 1. Reaction scheme of polymerizations. gion and propagates as a thermal wave (front) using the heat of polymerization. In SP, reaction starts within the dispersed monomer droplets via the very gradual decomposition of initiator $\left(10^{-3}\right.$ to $\left.10^{-5} / \mathrm{s}\right)$ followed by propagation and eventual termination.

\subsection{Velocity of front and percent conversion}

FP produces GMA-EGDM copolymer in the form of a cylinder (shape of the reactor). After the initial burst, front propagated unevenly for $1 \mathrm{~cm}$ and then progressed by a constant movement. The velocity of the front increased with the mole fraction of EGDM (increase in percent crosslink density). At higher crosslink density, a velocity lag was observed because of convective instabilities (Pojman et al 1992) which can be circumvented by dispersion of inert diluents like silica gel and $\beta$ cyclodextrin in the reaction mixture to increase the viscosity of the medium. Temperature profile of copolymerizations did not show appreciable difference in the front temperature relative to variances in monomer feed ratios. It was found to be between 165 and $182^{\circ} \mathrm{C}$. In contrast, all suspension copolymerizations were conducted isothermally at $70^{\circ} \mathrm{C}$.

At similar monomer feed ratios, the two copolymerizations differed markedly in the relative yields of the copolymers and the rate of copolymerization. Table 2 shows the conversion in FP is in the $90-97 \%$ range in a reaction time lasting $10-15 \mathrm{~min}$. In SP the conversions were 62$69 \%$ in $3 \mathrm{~h}$. This marked difference is because reaction in FP is initiated by the complete decomposition of the initiator which proceeds rapidly and locally, picking up most neighbouring reactive monomeric species. In SP, reaction is triggered by decomposition of a minute fraction of initiator present $\left(10^{-5}\right.$ to $\left.10^{-3} / \mathrm{s}\right)$ and very rapidly reaches a slow but a steady rate. The reaction needs to be conducted for a long time to reach near quantitative conversions. Maximum yield of $68.9 \%$ was obtained by SP at $200 \%$ CLD.

\subsection{Epoxy number}

The concentration of reactable surface epoxy groups in the two sets of networked, crosslinked GMA-EGDM copolymers decreased predictably with increasing crosslink density (increasing mole fraction of EGDM in the copolymerization recipe). However, a difference is noted between copolymers formed by the two methodologies (table 3 ). The copolymers formed by FP give considerably lower epoxy number except for copolymer with $200 \%$ CLD. This indicates that at the high temperature encountered in FP the selectivity of polymerization occurring exclusively by the coupling of olefinic double bonds is partially lost. In the frontal polymerization of acrylamide, this leads to partial loss of amide groups through imidiza- 
tion (Pojman et al 2000). Here, it leads to partial loss of epoxy groups through etherification. The level of such side reactions are not high enough to be picked up by infrared spectroscopy. This is plausible since the reaction temperature in FP is very high $\left(>160^{\circ} \mathrm{C}\right)$. At this temperature the decomposition rate of AIBN will be nearly quantitative. The reactivity of the radicals at such high temperatures will be very high and as a consequence the selectivity will be marginally lost. Transfer to hydrogen of tertiary methyl of epoxy group will take place resulting in the eventual opening of epoxy group.

\subsection{IR spectroscopy}

As indicated above, IR spectroscopy reveals no significant difference between copolymers of the two sets. The signals of the representative sample from both schemes (CLD 100\%) gives the characteristic signals of carbonyl carbon around (vs C=O) $1725-1730 \mathrm{~cm}^{-1}$, epoxide group (vs C-O-C) at 1200,900 and $800 \mathrm{~cm}^{-1}$ and absence of $\mathrm{C}=\mathrm{C}$ peak at 1600 and $1500 \mathrm{~cm}^{-1}$ (table 4) noted in respective monomers.

\subsection{Porosity, surface area and morphology}

The comparative data of pore volume and surface area for GMA-EGDM copolymers by FP and SP are presented in tables 5 and 6 . Mercury porosimetry in the pressure range $0-4000 \mathrm{~kg} / \mathrm{cm}^{2}$ provides good estimates of pore size and pore size distribution in the range 10,500-
$352 \mathrm{~nm}$ (Mikhail and Robens 1983). It is well established that smaller pores are generated at higher temperature (Svec and Frechet 1995). At front temperature, the larger the number of free radicals produced the larger the number of nuclei and globules formed. Because the amount of monomers in the system is the same for each polymerization, a higher number of globules translate into a smaller size. Moreover, the porosity in FP is a consequence of osmotic pressure generated by monomer (which acts as porogen) and increase in pressure by evolution of gaseous product by AIBN. Representative graph of $\mathrm{d} V / \mathrm{d} l o g P$ vs $\log r$ (figure 2) at $25 \%$ CLD of FP and SP shows the regular pore size distribution profile of copolymer by FP, which also clearly indicates the presence of large number of small pores in the range below $10 \mathrm{~nm}$.

Plots of internal pore volume $(\mathrm{mL} / \mathrm{g})$ (figure 3 ) and surface area $\left(\mathrm{m}^{2} / \mathrm{g}\right)$ (figure 4$)$ vs CLD (\%) show no trend in internal pore volume but slightly increasing trend in surface area (for FP). Porous morphology and formation of meso- and macroporous structures are strongly dependent on type and volume of porogen used. In the absence of an added porogen, the number of meso and macropores are few. Copolymers by SP are, therefore, free of pores in the size exceeding $352 \mathrm{~nm}$ and at $100 \%$ CLD the maximum pore volume obtained is only $0.019 \mathrm{~mL} / \mathrm{g}$. Surface area measurements show dramatic differences between the two sets of copolymers of similar size range (150$450 \mathrm{~nm}$ ). Surface area for the copolymer with $25 \%$ CLD, by SP, due to micro- and meso-pores was found to be the maximum $\left(5.91 \mathrm{~m}^{2} / \mathrm{g}\right)$.

Table 2. Per cent conversion in copolymerization of GMA with EGDM by frontal (FP) and suspension polymerization (SP).

\begin{tabular}{lcccccc}
\hline CLD (\%) & 25 & 50 & 75 & 100 & 150 & 200 \\
\hline Conversion (FP) & 92.27 & 94.16 & 90.46 & 94.92 & 91.73 & 97.43 \\
Conversion (SP) & 62.04 & 64.12 & 64.05 & 65.32 & 64.07 & 68.94 \\
\hline
\end{tabular}

Table 3. Comparison of GMA-EGDM copolymers prepared by frontal (FP) and suspension polymerizations for epoxy number.

\begin{tabular}{lcccc}
\hline CLD (\%) & 25 & 50 & 100 & 200 \\
\hline Epoxy number FP (mmol/g) & 3.92 & 2.61 & $2 \cdot 12$ & 1.79 \\
Epoxy number SP (mmol/g) & 4.74 & 3.59 & 2.83 & 1.36 \\
\hline
\end{tabular}

Table 4. Typical infrared absorption bands in GMA-EGDM copolymers prepared by frontal (FP) and suspension polymerization (SP).

\begin{tabular}{lcc}
\hline Vibrations/stretching & IR peaks of FP $\left(\mathrm{cm}^{-1}\right)$ & IR peaks of SP $\left(\mathrm{cm}^{-1}\right)$ \\
\hline C=O carbonyl carbon & 1730 & 1726 \\
Epoxy group & $801,909,1195$ & $807,900,1202$ \\
C-O-C stretching & 1091 & 1093 \\
\hline
\end{tabular}


Table 5. Internal pore volume of the GMA-EGDM copolymers prepared by frontal (FP) and suspension polymerization (SP).

\begin{tabular}{lcccccc}
\hline CLD $(\%)$ & 25 & 50 & 75 & 100 & 150 & 200 \\
\hline FP [Pore volume (mL/g)] & 0.037 & 0.035 & 0.026 & 0.042 & 0.025 & 0.037 \\
SP [Pore volume (mL/g)] & 0.019 & 0.013 & 0.010 & 0.018 & 0.018 & 0.016 \\
\hline
\end{tabular}

Table 6. Surface area of the GMA-EGDM copolymers prepared by frontal (FP) and suspension polymerization (SP).

\begin{tabular}{lrrrrrr}
\hline CLD (\%) & \multicolumn{1}{c}{5} & \multicolumn{1}{c}{50} & \multicolumn{1}{c}{75} & 100 & 150 & \multicolumn{1}{c}{200} \\
\hline FP [surface area $\left.\left(\mathrm{m}^{2} / \mathrm{g}\right)\right]$ & $40 \cdot 20$ & 40.5 & 42.66 & $45 \cdot 10$ & 45.90 & 46.99 \\
SP [surface area $\left.\left(\mathrm{m}^{2} / \mathrm{g}\right)\right]$ & 5.91 & 4.4 & $5 \cdot 13$ & 5.82 & 5.35 & 5.93 \\
\hline
\end{tabular}

Along with porogen and crosslinker, temperature also affects both specific surface area and pore volume (Svec and Frechet 1995). At front temperature, the polymerization reaction is very fast and more growing chains are transformed into individual globules rather than being captured by the primary nuclei. These globules are small and therefore, their surface is larger. Copolymer with $200 \%$ CLD, showed a maximum surface area of $46.99 \mathrm{~m}^{2} / \mathrm{g}$. This is due to micropores in the range below $352 \mathrm{~nm}$, which are not detected by mercury porosimetry. In contrast to the specific surface area, the changes in total pore volume are small and vary only from 0.025 to $0.042 \mathrm{~mL} / \mathrm{g}$.

The porosity and concentrations of surface epoxy groups are defined by the application. While polymer supports for enzyme immobilization require macroporous structures, chromatographic materials for chiral resolution of low molar mass racemic mixtures require large surface area. Polymers obtained by FP without porogen are ideally suited to be base polymers for chiral resolution, since these have good surface area. These were translucent indicating the size of internal agglomerates are smaller than $200 \mathrm{~nm}$. Monomer and nitrogen gas evolved due to initiator during the polymerization play the role of porogen. The copolymers obtained by SP, on the other hand, are transparent indicating that the copolymers are nearly nonporous. These results indicate that it is necessary to have a porogen in copolymerization mixture to produce macroreticular polymers by SP.

SEM reveals considerable differences in surface morphologies (figures 5 and 6). FP proceeds in a localized region and copolymer is formed in the form of a cylinder. Grinding leads to irregular beads. The irregular morphology of the ground polymer sample G4111F synthesized by FP is shown in figure 5. SP was conducted under constant agitation. This leads to the formation of perfect spherical beads. SEM micrograph (figure 6) indicates the uniform morphology of the copolymer G411S bead. However, at high resolution, polymers by FP are seen to have

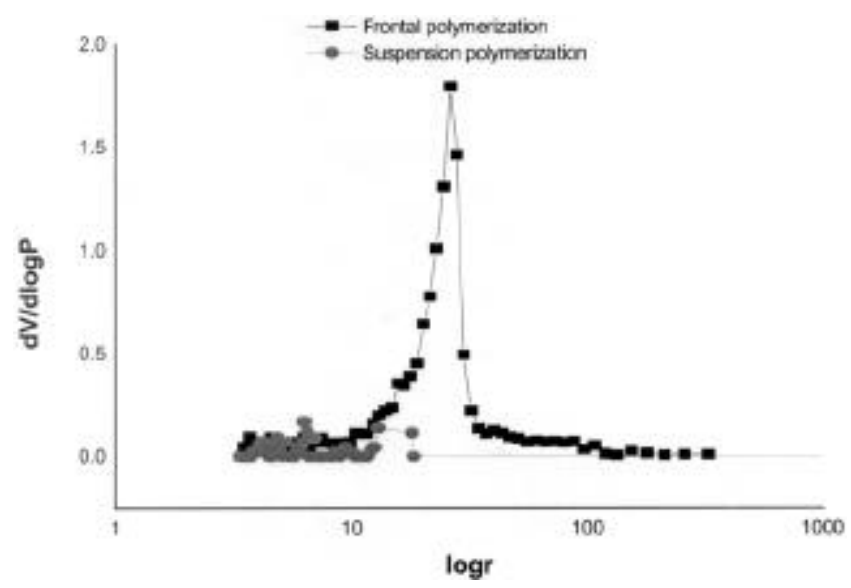

Figure 2. Differential pore size distribution of GMA-EGDM copolymers prepared by frontal (FP) and suspension polymerization (SP) at $25 \%$ CLD ( $\mathrm{r}$ is in $\mathrm{nm}$ ).

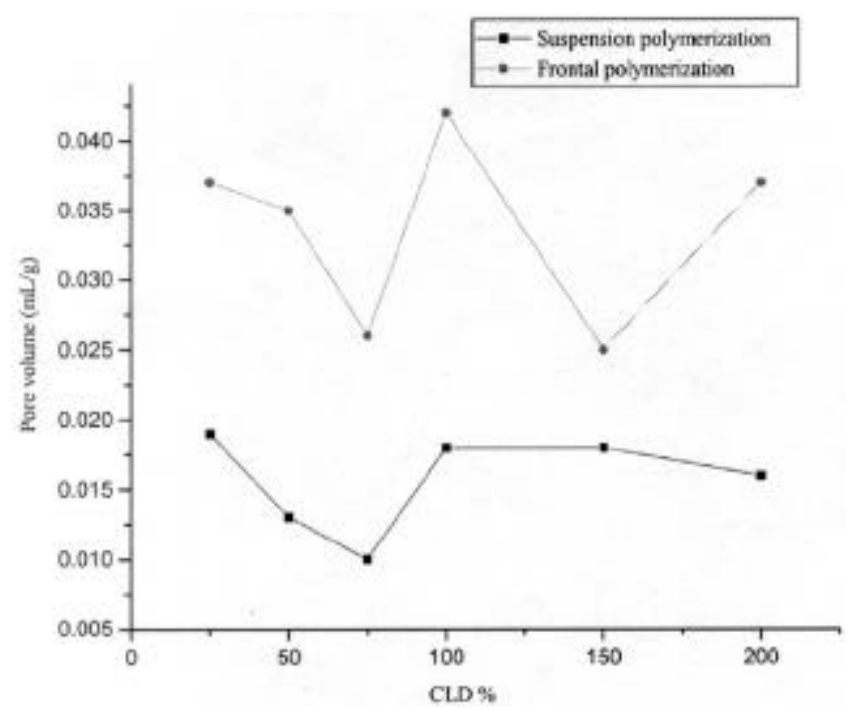

Figure 3. Comparison between internal pore volume of GMAEGDM copolymers prepared by frontal (FP) and suspension polymerization (SP). 


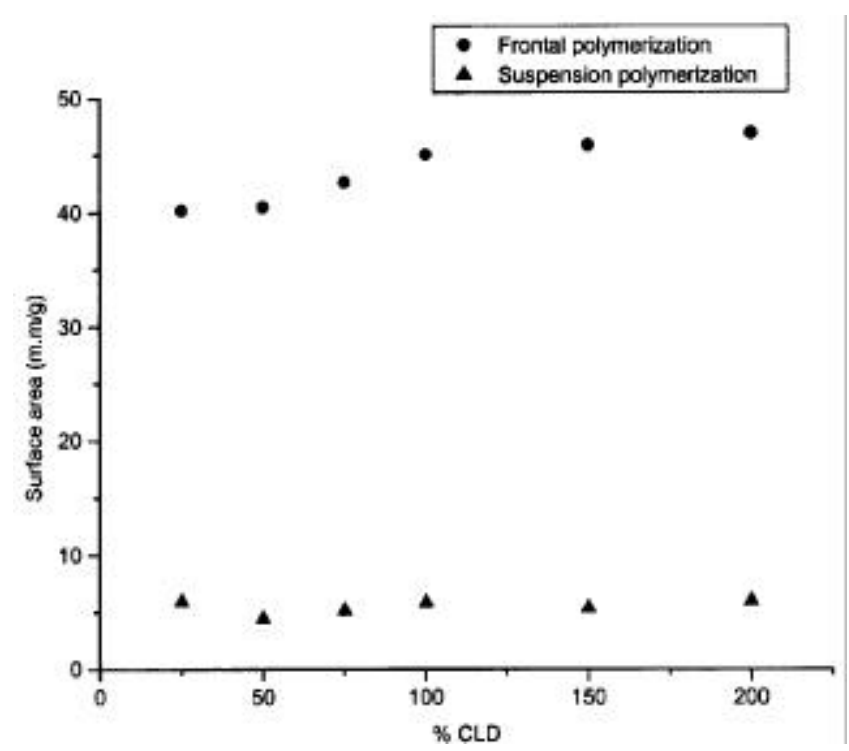

Figure 4. Comparison of surface area between GMA-EGDM copolymers prepared by frontal (FP) and suspension polymerization (SP).

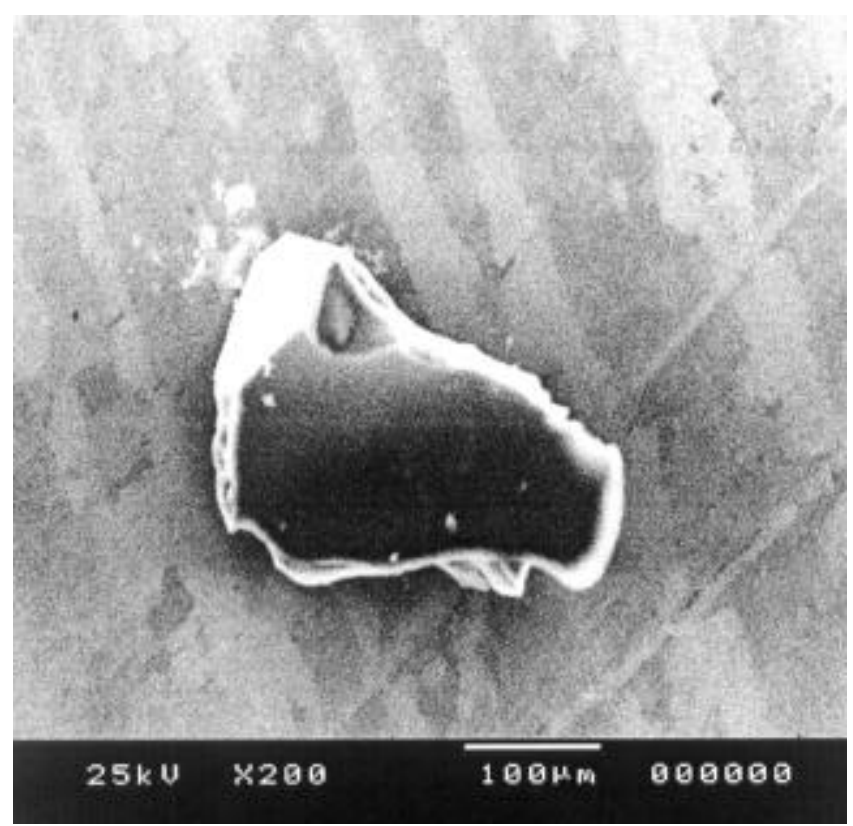

Figure 5. Scanning electron micrograph of GMA-EGDM copolymer by frontal polymerization (G4111F, 100\% CLD).

porous structure (figure 7) while SP products are transparent and nonporous.

\section{Conclusions}

The possibility of using self propagating frontal polymerization to produce porous material has been investigated. Frontal polymerization is advantageous over suspension polymerization in terms of reaction time, percent

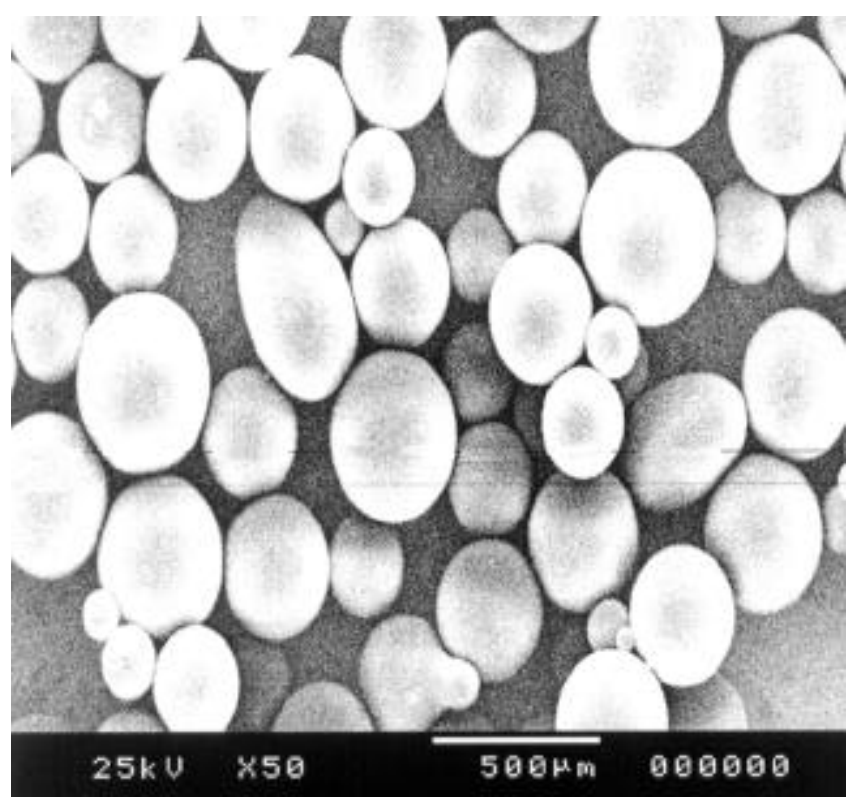

Figure 6. Scanning electron micrograph of GMA-EGDM copolymer by suspension polymerization (G4111S, 100\% CLD).

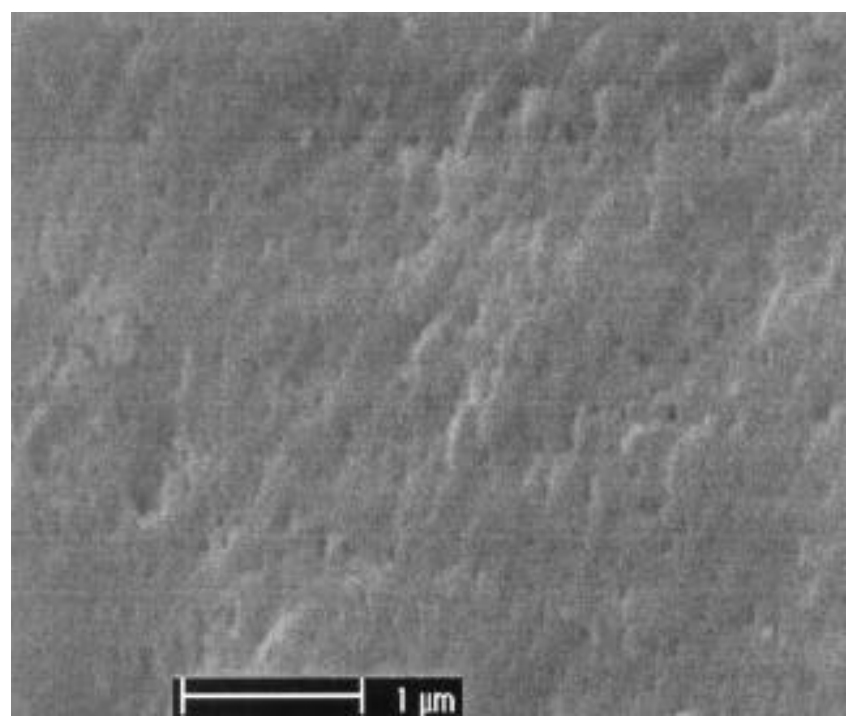

Figure 7. Internal porous structure obtained by taking the sectional micrograph of FP product (G4111F, 100\% CLD) by scanning electron microscopy.

conversion and porosity. With the increase of cross-link density, the pore volume and surface area increases while surface epoxy number decreases.

The crosslink density is the most convenient variable to adjust the pore size distribution and surface area in network polymers. Copolymer by FP is translucent while similar copolymer by SP without porogen is almost transparent indicating almost non porous material. FP rapidly produces porous polymer in cylindrical form suitable as base materials for chromatographic supports, although surface morphologies are inferior. 


\section{References}

Akolekar D B, Hind A R and Bhargava S K 1998 J. Colloid. Interface. Sci. 701629

Bhave R R 1991 Inorganic membranes; Synthesis, characteristics and application (New York: Van Nostrand Reinhold)

Chechilo N M and Enikolopyan N S 1975 Dokl. Phys. Chem. 221392

Chechilo N M, Khvilivitskii R J and Enikolopyan N S 1972 Dokl. Akad. Nauk SSSR 2041180

Davtyan S P, Arutiunian K A, Rozenberge B A and Enikolopyan N S 1975 Dokl. Akad. Nauk. 223687

Davtyan S P, Surkov N F, Rozenberge B A and Enikolopyan N S 1976 Dokl. Phys. Chem. 228435

Davtyan S P, Surkov N F, Rozenberge B A and Enikolopyan N S 1977 Dokl. Phys. Chem. 23264

Davtyan S P, Zirakov P V and Volison S A 1984 Russian Chem. Rev. $\mathbf{5 3} 150$

Davtyan S P, Begishev V P, Volpert V A and Molkin A Y 1985 Dokl. Akad. Nauk. 279909

Davtyan S P, Volpert V A, Megrabova I M and Begishev V P 1986 Combust. Expl. Shockwaves 21443

Davtyan S P, Babadzhahyan A S, Volpert V A and Megrabova I M 1989 Combust. Expl. Shockwaves 2523

Deleuze H, Schultze X and Sherrington D C 1998 Polymer 39 6109

Enikolopyan N S, Kozhushner M A and Khaunkaev B B 1974 Dokl. Phys. Chem. 217676

Fiori S and Mariani A 2003 Macromolecules 362674

Fulton S P, Afeyan N B and Regnier F E 1991 J. Chromatogr. 547452

Hamid M A, Naheed R, Fuzail M and Rehman E 1999 Eur. Polym. J. 351799

Hodge P and Sherrington D C 1980 Polymer supported reactions in organic synthesis (New York: Wiley)

Horak D, Svec F, Ilavsky M, Bleha M, Baldrian J and Kalal J 1981 Angew. Makromol. Chem. 95 109, 117

Khaunkaev B B, Kozhushner M A and Enikolopyan N S 1974 Dokl. Phys. Chem. 21484

Koike Y, Takezawa Y and Ohtsuka Y 1988 Appl. Opt. 27486

Lee H and Neville K 1967 Handbook of epoxy resins (New York: McGraw-Hill Book Company) p. 4

Lewandowski K, Murer P, Svec F and Fretchet J M J 1998a Anal. Chem. 701629

Lewandowski K, Svec F and Fréchet J M J 1998b J. Appl. Polym. Sci. 67597

Liang Y C, Svec F and Fréchet J M J 1997 J. Polym. Sci. Part A: Polym. Chem. 352631

Masere J, Lewis L L and Pojman J A $2001 \mathrm{~J}$. Appl. Polym. Sci. 80686

Maugh T M 1984 Science 223474

Mikhail R S and Robens E 1983 Microstructure and thermal analysis of solid surfaces (New York: Wiley Hyden Publications Ltd.) p. 161

Palm A and Novotny M V 1997 Anal. Chem. 694499

Perry M F, Volpert V A, Lewis L L, Nichols H A and Pojman J A 2003 Macromol. Theory Simul. 12276

Pojman J A 1991 J. Am. Chem. Soc. 1136284

Pojman J A, Craven R, Khan A and West W 1992 J. Phys. Chem. 967466

Pojman J A, Nagy I P and Salter C 1993 J. Am. Chem. Soc. 115 11044

Pojman J A, Nagy I P and Sike L 1995a J. Am. Chem. Soc. 117 3611

Pojman J A, Willis J, Fortenberry D V, Ilyashenko V M and Khan A 1995b J. Polym. Sci. Part A: Polym. Chem. 33643

Pojman J A, Curtis G and Ilyashenko V M 1996a J. Am. Chem. Soc. 1183783

Pojman J A, Ilyashenko V M and Khan A M 1996b J. Chem. Soc. Faraday Trans. 922825

Pojman J A, Elcan W, Khan A M and Mathias L M 1997 J. Polym. Sci. Part A: Polym. Chem. 35227

Pojman J A, Willis J, Fortenberry D V, Ilyashenko V M and Khan A 1998 Solvent-free synthesis by free-radical frontal polymerization (eds) T E Long and M O Hunt, ACS Symposium series 713 (Washington, DC: American Chemical Society) p. 140

Pojman J A, Willis J, Khan A M and West W W 2000 J. Polym. Sci. Part-A: Polym. Chem. 381129

Pojman J A, Popwell S, Fortenberry D I, Volpert V A (I) and Volpert V A (II) 2003 Nonlinear dynamics in frontal polymerization (eds) J A Pojman and Q Tran-Cong-Miyata, ACS symposium series 869 (Washington, DC: American Chemical Society) p. 106

Pujari N S, Vishwakarma A R, Pathak T S, Mule S A and Ponrathnam S 2004 Polym. Int. (to be published)

Sherrington D C 1998 Chem. Commun. 212275

Svec F and Frechet J M J 1995 Macromolecules 287580

Tanev P T, Chibwe M and Pinnavaia T J 1994 Nature 368321

Tennikov M B, Gazdina N V, Tennikova T B and Svec F 1998 J. Chromatogr. A798 55

Tredici A, Pecchini R and Morbidelli M 1998 J. Polym. Sci. Part A: Polym. Chem. 361117

Vivaldo-Lima E, Wood P E, Hamielec A E and Penlidis A 1997 Ind. Eng. Chem. Res. 36939

Washington R P and Steinbock O 2001 J. Am. Chem. Soc. 123 7933

White S R and Kim C 1992 Int. Sample Symp. Exhib. 37240

White S R and Kim C 1993 J. Reinforced Plastics Comp. 12520

Wijnhoven J E and Vos W L 1998 Science 281802

Xie S, Svec F and Frechet J M J 1997 J. Chromatogr. A775 65

Yuan H G, Kalfas G and Ray W H 1991 J. Macromol. Sci. Rev. Macromol. Chem. Phys. C31 215

Zhang Q, Wang P and Zhai Y 1997 Macromolecules 307874 